\title{
Graphene Thin Layers Formation on Monocrystalline Ni(111)/MgO(111) by Carbon Implantation and Annealing
}

\author{
F. Le Normand ${ }^{*}$, M. Benyahia ${ }^{1}$, C. Speisser ${ }^{1}$, D. Muller ${ }^{1}$, F. Aweke ${ }^{1}$, G. Gutierrez¹, \\ J. Arabski², G. Morvan ${ }^{3}$ \\ ${ }^{1}$ ICube-Laboratoire des Sciences de I'Ingénieur, de I'Informatique et de l'Imagerie, Université de Strasbourg, \\ Strasbourg Cedex, France \\ ${ }^{2}$ IPCMS - Institut de Physique et de Chimie des Matériaux de Strasbourg, Strasbourg Cedex, France \\ ${ }^{3} \mathrm{LHyGeS}$-Laboratoire d'Hydrologie et de Géochimie de Strasbourg, Strasbourg Cedex, France \\ Email: francois.le-normand@unistra.fr
}

Received 9 March 2015; accepted 27 March 2015; published 8 April 2015

Copyright (C) 2015 by authors and Scientific Research Publishing Inc.

This work is licensed under the Creative Commons Attribution International License (CC BY).

http://creativecommons.org/licenses/by/4.0/

(c) (7)

\section{Abstract}

The objectives of this study are the elaboration of graphene by 1) carbon implantation at moderate temperature $(873 \mathrm{~K})$ into a monodomain epitaxially-grown $\mathrm{Ni}(111)$ film deposited on a reusable $\mathrm{MgO}(111)$ substrate, followed by 2 ) carbon surface precipitation by thermal treatment. The growth of the nickel film by molecular beam epitaxy has been monitored by Reflection High Energy Electron Diffraction. The film morphology has been studied by Electron Back-Scattered Diffraction, Atomic Force Microscopy and Rutherford Backscattering Spectroscopy in the tunneling mode. In the optimized conditions corresponding to a germination step at $633 \mathrm{~K}$ followed by a step growth at $873 \mathrm{~K}$ and a post-annealing treatment at $1023 \mathrm{~K}$ monocrystalline Ni(111) [1 $\overline{10}$ ] //MgO(111) $[\overline{110}]$ films are prepared, exhibiting monodomain swith high structural and orientation qualities. ${ }^{13} \mathrm{C}$ implantation into these nickel films is subsequently achieved at $873 \mathrm{~K}$ with energy within $20-50 \mathrm{keV}$ and a carbon dose equivalent to 4 monolayers of graphene $\left(1.4 \times 10^{16}\right.$ at $/ \mathbf{c m}^{2}$ ). Carbon diffuses mainly towards the surface, forming thin layers graphene. Compared to a Ni polycrystalline film the graphene fragments are larger and better facetted. The carbon amounts inside the nickel films at different steps, as well as the carbon amount at the surface, have been measured by Nuclear Reaction Analysis and X-ray Photoelectron Spectroscopy, respectively. The results show that, in addition to implanted ${ }^{13} \mathrm{C}$, some amounts of ${ }^{12} \mathrm{C}$ is incorporated at different steps of the process and is involved in the formation of the graphene mono-

${ }^{*}$ Corresponding author.

How to cite this paper: Le Normand, F., Benyahia, M., Speisser, C., Muller, D., Aweke, F., Gutierrez, G., Arabski, J. and Morvan, G. (2015) Graphene Thin Layers Formation on Monocrystalline Ni(111)/MgO(111) by Carbon Implantation and Annealing. Graphene, 4, 21-37. http://dx.doi.org/10.4236/graphene.2015.42003 
layers, as shown by ${ }^{13} \mathrm{C} /{ }^{12} \mathrm{C}$ Raman mappings. We finally discuss different mechanisms for carbon diffusion and surface segregation, considering the size and thickness distributions of the thinlayers graphene.

Keywords

Graphene, Nickel, Monocrystalline Films, Ion Implantation, Raman Spectroscopy

\section{Introduction}

Graphene is a 2D planar material of hexagonal structure comparable to a honeycomb network [1] [2]. This particular structure infers outstanding properties like very large electrical [3] and thermal [4] conductivities, high planar Young modulus and high flexibility [5], large transparency [6]. In the domain of electronics, we are at a step where other solutions must be found to size limitations of silicon-based electronics. Graphene may provide this alternative, owing to its thickness and the high mobility of the charge carriers [7]. However many applications require high quality, large size, low temperature and thickness-controlled materials. To reach these objectives at a moderate cost, the growth of graphene by Chemical Vapor Deposition (CVD) and related processes using metallic catalyst appears very promising. However a high quality metallic surface is needed in order to reach these aforementioned goals. Indeed high quality graphene layers can be obtained on bulk monocrystals like Ni(111) [8]. But this way can be discarded for applications owing to the expensive cost of the monocrystal. On the other hand, the use of cheap polycrystalline Cu foils yields rather uniform and large size graphene layers, but at high temperatures, typically 1273 - $1323 \mathrm{~K}$ [9] [10], and multiple domains are observed due to the presence of grain boundaries on the substrate [11]. Finally the graphene films must generally be transferred on another surface pertinent for some specific applications. An alternative and intermediate solution would be the growth of supported monocrystalline metallic films such as $\mathrm{Ni}(111)$ [12] or $\mathrm{Cu}(111)$ [13]-[15] on substrates such as $\mathrm{MgO}(111)$ or $\alpha-\mathrm{Al}_{2} \mathrm{O}_{3}(0001)$. This solution has the advantage to grow high-quality graphene at moderate temperatures and at a lower cost, while preserving the high quality of the film. Also the substrate can be easily reused by further dilution of the metallic film [12].

Here we report the preparation of monocrystalline $\mathrm{Ni}(111) / \mathrm{MgO}(111)$ oriented films and the subsequent growth of graphene-like or thin layers graphite (TLG) by an implantation process of carbon ions at high energy and at moderate temperatures (873 K). The carbon implantation process to form graphene film has been soon described in the literature, but using polycrystalline Ni films [16]-[23]. Then high-quality graphene or TLG are obtained but with variable thickness and weak size domains. Generally better quality graphene and TLG are obtained on monocrystalline than on polycrystalline $\mathrm{Ni}$ [24]. One advantage of the implantation technique is the possibility to get a graphene layer at an interface by deep implantation rather than at the surface, and thus to avoid the risky step of graphene transfer. On the other hand, the growth of nickel on $\mathrm{MgO}$ is well-documented in the literature, for the production of metallic films with specific magnetic properties, and more recently for providing a proper substrate for graphene growth [25]. The Table 1 summarizes different parameters of the Ni(111) growth on $\mathrm{MgO}(111)$. In spite of a large misfit (16\%), the Ni accommodates the $\mathrm{MgO}(111)$ substrate through an atomic rearrangement involving a lattice matching in the ratio 6:5 for the growth of textured $\mathrm{Ni}(111) / \mathrm{MgO}(111)$ [25]. The growth is clearly 3D with a progressive coalescence of the oriented grains. The comparable dilatation coefficients may prevent delamination of the films during cooling.

In this paper, we will show that the graphene growth through ion implantation yields larger size TLG fragments with a better control of carbon incorporation on monocrystalline Ni layers compared to polycrystalline ones. However the incorporation of ${ }^{12} \mathrm{C}$ limits the control of the size and thickness of the graphene fragments.

\section{Experimental}

Different steps of the experiment have been already reported elsewhere [22] [23] and the overall pathway is summarized in Figure 1, including Ni film preparation (top), carbon implantation and thermal annealing (bottom). Finally the carbon has been etched by Reactive Ion Etching and the metallic film is dissolved into a 2 
Table 1. Main parameters of the graphene/Ni(111)/MgO(111).

\begin{tabular}{cccccc}
\hline Element & $\begin{array}{c}\text { Bulk lattice } \\
\text { type }\end{array}$ & $\begin{array}{c}\text { Bulk lattice parameter } \\
(\mathrm{nm}) \text { at RT }\end{array}$ & $\begin{array}{c}\text { Surface (111) lattice } \\
\text { parameter (nm) at RT }\end{array}$ & $\begin{array}{c}\text { Dilatation coefficient } \\
10^{-6}\left(\mathrm{~K}^{-1}\right) \text { [T range in K] [ref] }\end{array}$ & $\begin{array}{c}\text { Carbon absorption } \\
\text { at 873 K (wgt\%) }\end{array}$ \\
\hline $\mathrm{Ni}$ & Cfc (bulk) & 0.3523 & 0.249 & 15.5 & 0.04 \\
$\mathrm{MgO}$ & Cfc (bulk) & 0.4216 & 0.298 & $1300-873][26]$ & 0 \\
Graphene & $\begin{array}{c}\text { Hexagonal } \\
\text { (surface) }\end{array}$ & - & 0.2456 & $-1[273-673][28]$ \\
$1[673-1073][29]$ & - \\
\hline
\end{tabular}

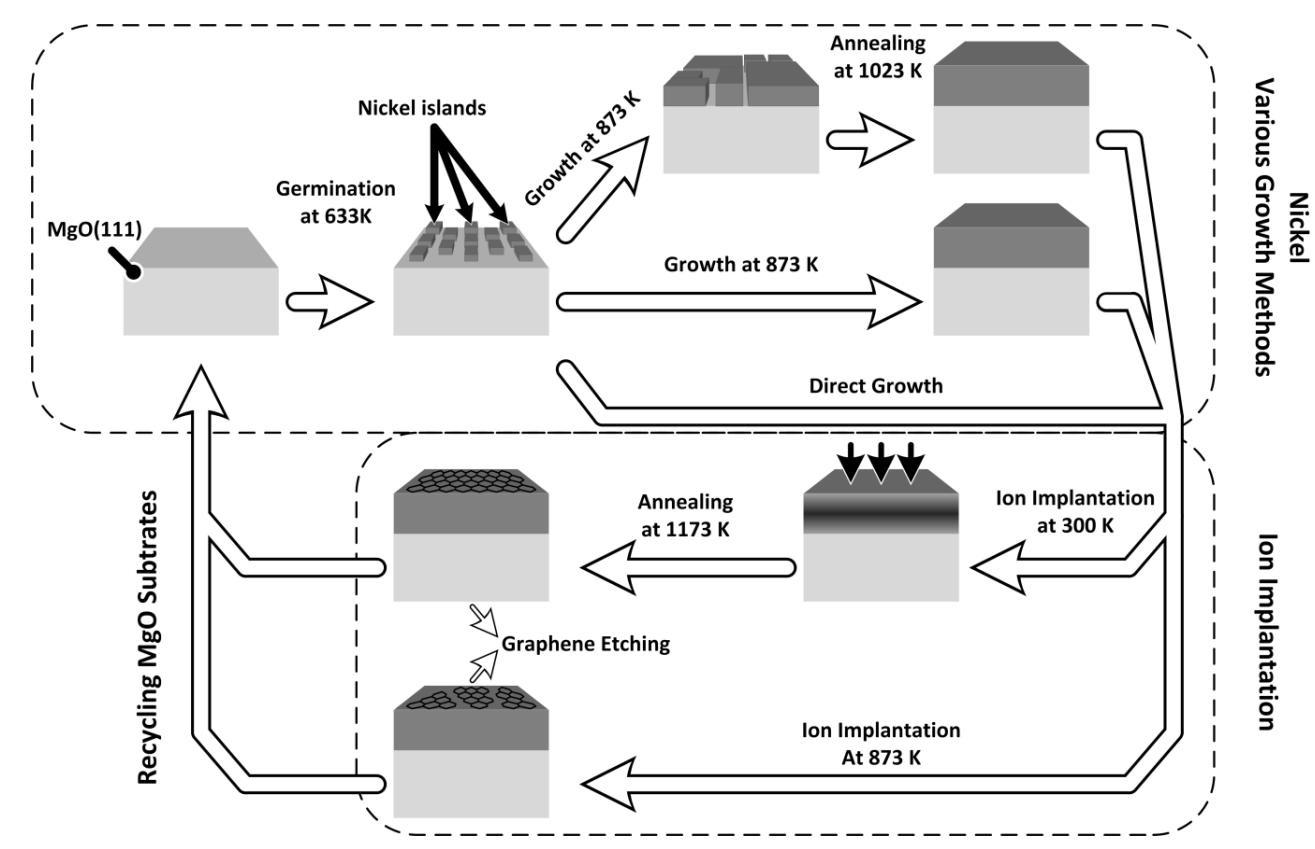

Figure 1. Schematic preparation of the TLG/Ni(111)/MgO(111) samples including Ni film preparation (top) and carbon implantation and thermal annealing (bottom).

$\mathrm{M} \mathrm{FeCl}_{3}$ ethanol solution, according to a process described in the literature [12], so that these substrates can be reused.

\subsection{Growth of Heteroepitaxial $\mathrm{Ni}(111) / \mathrm{MgO}(111)$ Films}

$\mathrm{Ni}$ films were evaporated by Molecular Beam Epitaxy (MBE) in a UHV chamber (residual pressure less than $10^{-9} \mathrm{mbar}$ ) equipped with a RHEED. Ni atoms were evaporated with an electron gun $(10 \mathrm{~kW})$ from a Ni ingot in a crucible (purity 99.999\%; Root Mean Square roughness (RMS) $2.29 \mathrm{~nm}$ ) with a working pressure of around $10^{-8}$ mbar. The internal walls were continuously cooled down to $77 \mathrm{~K}$. During the growth the Ni films thickness was measured by a quartz balance and ex situ checked by Rutherford Backscattering Spectrometry (RBS). The deposition rate was estimated to $0.03 \mathrm{~nm} \cdot \mathrm{s}^{-1}$. $\mathrm{MgO}(111)\left(10 \times 10 \times 0.5 \mathrm{~mm}^{3}\right)$ samples were purchased from Crystal GmBH. They were preliminary cleaned with an ultrasonic bath filled with acetone and isopropanol. Each operation was repeated two times for $10 \mathrm{~min}$. Then the substrate is set on a rotating Molyblock substrate holder into the UHV chamber and subsequently cleaned at $773 \mathrm{~K}$ (12 hours) and $1023 \mathrm{~K}$ (1 hour) according to [24]. The temperature was measured by contacting a thermocouple settled on the backside of the substrate holder. The growth was monitored by RHEED with $20 \mathrm{kV}$ electrons. RHEED observations along the azimuth [1 $\overline{1} 0]$ of $\mathrm{MgO}$ have been monitored at the different steps of the growth, i.e. preparation of the MgO substrate, germination, growth, coalescence and final annealing. The main characteristics of the samples prepared are summarized in Table 2. 
Table 2. Some characteristics of the $\mathrm{Ni} / \mathrm{MgO} \_\mathrm{X}(1 \leq \mathrm{X} \leq 6)$ samples.

\begin{tabular}{|c|c|c|c|c|c|c|c|c|c|}
\hline \multirow{3}{*}{ Sample } & \multicolumn{3}{|c|}{ Deposited thickness } & \multirow{3}{*}{$\begin{array}{l}\text { Thickness } \\
\text { (nm) } \\
\text { determined } \\
\text { by RBS }\end{array}$} & \multirow{3}{*}{$\begin{array}{c}\text { Annealing } \\
(\mathrm{K}) \\
(60 \mathrm{~min})\end{array}$} & \multirow{3}{*}{$\begin{array}{c}\text { Carbon } \\
\text { implantation } \\
\text { energy }(\mathrm{keV})\end{array}$} & \multirow{3}{*}{$\begin{array}{c}\text { Carbon } \\
\text { implantation } \\
\text { temperature } \\
\text { (K) }\end{array}$} & \multirow{2}{*}{\multicolumn{2}{|c|}{$\begin{array}{l}\text { Roughness measured } \\
\text { by AFM (nm) }\end{array}$}} \\
\hline & \multicolumn{2}{|c|}{ Nucleation } & \multirow{2}{*}{$\begin{array}{c}\text { Growth } \\
873 \mathrm{~K}(\mathrm{~nm})\end{array}$} & & & & & & \\
\hline & $(\mathrm{nm})$ & $(\mathrm{K})$ & & & & & & Before implantation & After implantation \\
\hline Ni/MgO_1 & 200 & 605 & 0 & 186 & - & 20 & 873 & 17 & 19 \\
\hline Ni/MgO_2 & 300 & 605 & 0 & 275 & - & 20 & 873 & 3.8 & 4.1 \\
\hline Ni/MgO_3 & 300 & 635 & 0 & 325 & - & 20 & 873 & 2.4 & 6.2 \\
\hline Ni/MgO_4 & 100 & 635 & 200 & 291 & - & 50 & 873 & 3.1 & 3.9 \\
\hline Ni/MgO_5 & 100 & 635 & 300 & 419 & 1015 & 50 & 873 & 2.7 & 4.7 \\
\hline Ni/MgO_6 & 100 & 635 & 200 & 291 & $1173^{\mathrm{a}}$ & 50 & 300 & 3.1 & $3.2^{\mathrm{a}}$ \\
\hline
\end{tabular}

${ }^{a}$ After carbon implantation at $300 \mathrm{~K}$.

Samples, further named as $\mathrm{Ni} / \mathrm{MgO} \mathrm{X}(1 \leq \mathrm{X} \leq 6)$, were prepared by a four step process including a common cleaning step, a germination step at $605 \mathrm{~K}(\mathrm{X}=1-2)$ or $635 \mathrm{~K}(3 \leq \mathrm{X} \leq 6)$ followed by a growth step at $873 \mathrm{~K}$ $(\mathrm{X}=4-6)$ and a final annealing at $1015 \mathrm{~K}(\mathrm{X}=5)$ or $1173 \mathrm{~K}(\mathrm{X}=6)$. This last step was achieved in a UHV furnace (base pressure $2 \times 10^{-9}$ mbar) equipped with a silica reactor. Therefore the annealing was achieved at three temperatures: 1$)$ during ion implantation at $873 \mathrm{~K}(\mathrm{X}=1$ - 4); 2) Post-thermal treatments at $1015 \mathrm{~K}(\mathrm{X}=5)$ and 3) at $1173 \mathrm{~K}(\mathrm{X}=6)$ after room temperature implantation. Each preparation included two samples. The first sample was used solely for the steps of the process and carefully stored in a desiccator meanwhile. The second one was devoted to characterization studies (EBSD, SEM, RBS, NRA,...) between each step of the process. The reason for this doubling was that deposition of surface hydrocarbon and carbon incorporation as impurity might occur during handling and characterization studies. However, unless otherwise stated, we did not find significant differences in carbon content between the two sets of samples. Finally, as we want to minimize the thickness of the nickel films, the overall thickness of the samples does not exceed $420 \mathrm{~nm}$.

\subsection{Carbon Implantation on $\mathrm{Ni} / \mathrm{MgO}$ Samples}

The Ni/MgO samples were implanted with ${ }^{13} \mathrm{C}$ ions at a fluence of $1.4 \times 10^{16} \mathrm{at} \cdot \mathrm{cm}^{-2}$ from a ${ }^{13} \mathrm{CO}$ source (EURISO-TOP, purity 99\%), corresponding to around 4 equivalent graphene monolayers (EGM), as one EGM is quoted to $3.6 \times 10^{15} \mathrm{at}^{\cdot} \mathrm{cm}^{-2}$ for a graphene surface. The implantation was carried out at a vacuum pressure of 2 $\times 10^{-6} \mathrm{mbar}$ and at $873 \mathrm{~K}$ for Ni/MgO_X samples $(1 \leq \mathrm{X} \leq 5)$ using a heated substrate holder in Inconel alloy. The duration of the implantation process was around 1 hour. The heating and cooling rates were around 20 $\mathrm{K} / \mathrm{min}$ for the implantation occurring at $873 \mathrm{~K}$. The temperature at the sample surface was calibrated by using both a thermocouple settled on the back of the substrate holder and an extinction pyrometer in front of the sample. The sample Ni/MgO_6 was implanted with 4 EGM at room temperature (however the true temperature during the carbon implantation was estimated to around $350 \mathrm{~K}$ ) followed by a UHV thermal annealing at $1173 \mathrm{~K}$.

\subsection{Characterizations of the Samples}

Ion Beam analyses were performed using the 4 MV Van De Graff accelerator facility of ICube. RBS and NRA were carried out either in a random or in a channeling mode. In the last case, the samples were settled on a goniometer to accurately tune the angle $\theta$ for which the backscattered ions can be channeled with a resolution of the order of $10 \mathrm{keV}$.

RBS experiments were carried out with $2 \mathrm{MeV}$ incident alpha particles $\left(1 \times 1 \mathrm{~mm}^{2}\right)$, a $10 \mathrm{nA}$ intensity current, and a $160^{\circ}$ scattering angle. The pressure inside the analysis chamber during the analysis was around $10^{-6} \mathrm{mbar}$. The thicknesses of the Ni films were determined by RBS in the random mode before and after the implantation and/or thermal post-treatments. RBS in the channelling mode was used to determine the crystallisation level of the Ni films.

Moreover, to determine the evolution of ${ }^{12} \mathrm{C}$ (as impurity), ${ }^{13} \mathrm{C}$ and $\mathrm{O}$ concentrations after each treatment, Nuclear Reaction Analyses (NRA) were performed. The ${ }^{12} \mathrm{C}(\mathrm{d}, \mathrm{p}){ }^{13} \mathrm{C},{ }^{13} \mathrm{C}(\mathrm{d}, \mathrm{p}){ }^{14} \mathrm{C},{ }^{16} \mathrm{O}\left(\mathrm{d}, \mathrm{p}_{1}\right){ }^{17} \mathrm{O}$ and ${ }^{16} \mathrm{O}(\mathrm{d}$, 
$\left.\mathrm{p}_{0}\right)^{17} \mathrm{O}$ reactions were recorded with a $900 \mathrm{keV}$ deuterons beam on a $1 \times 1 \mathrm{~mm}^{2}$ area. A $150 \mathrm{~mm}^{2}$ silicon surface barrier detectors was mounted at an angle of $150^{\circ}$ to the beam direction resulting in a total solid angle of $\Omega-60$ msr. An absorber of $11.8 \mu \mathrm{m}$ Mylar foil was attached above the detector to stop the alpha particles generated by the ${ }^{16} \mathrm{O}(\mathrm{d}, \alpha){ }^{14} \mathrm{~N}$ reaction and the backscattered deuterons particles. The experimental spectra were calibrated by using bare $\mathrm{SiO}_{2}$ and $\mathrm{SiC}$ samples for oxygen and carbon nuclear reactions, respectively, and the spectra were then simulated with the SIMNRA software [30]. Due to the weak depth resolution of the NRA, it is not possible to differentiate surface or interface carbon from bulk carbon. Therefore this technique is allowed to determine only the overall carbon amount.

To characterize the surface of the implanted samples, SEM observations were carried out using a Scanning Electron Microscope (JEOL 6700F-2001) provided with a field emission gun in the Secondary Electron Image mode at low voltages $(1-3 \mathrm{kV})$ more sensitive to the chemical contrast. The pressure in the analysis chamber was determined at around $10^{-6}$ mbar. The electron backscattered diffraction (EBSD) diagrams were acquired using a TESCAN (Vega II XMU) scanning electron microscope, provided with a tungsten electron gun and equipped with an EDAX-TSL EBSD package, operating at $30 \mathrm{kV}$ and a working distance of $23 \mathrm{~mm}$. The pressure in the observation chamber was around $10 \mathrm{~Pa}$. EBSD patterns (i.e. Kikuchi lines) were calibrated using a Si single crystal (space group Fm3m with a lattice spacing a $=5.431 \AA$ ). Kikuchi diagrams had been clearly observed at $30 \mathrm{kV}$ and point analyses with more than 100 points were performed to check the orientation of the nickel plans. Data were processed with an OIM analysis (TSL/EDAX) software. Typical EBSD images are reported in Supplementary Material 1 (SM1).

The Atomic Force Microscopy (AFM) measurements were performed on a NT-MDT Stand Alone SMENA set-up used in the resonant mode AFM Semicontact. Non-Contact Mikro Mash NSC 18 cantilever scanning probes were used with a minimum scanning step of $0.012 \mathrm{~nm}$. Root Mean Squares (RMS) are determined on full images of size $100 \mu \mathrm{m}^{2}$.

Raman spectroscopy was carried out using a Horiba spectrometer LabRam at $532 \mathrm{~nm}$ equipped with a CCD camera. Spectra and images were recorded using a $\times 100$ magnification, with a power energy of $0.9 \mathrm{~mW}$ and a fluence of $2.25 \mathrm{~mW} \cdot{\mu \mathrm{m}^{-2}}^{2}$ in order to avoid damages to the graphene film.

X-ray photoemission spectra were recorded with a $150 \mathrm{~mm}$ hemispherical detector VSW with an overall resolution of $0.65 \mathrm{eV}$ under a base pressure of $5 \times 10^{-9}$ mbar using a monochromatic $\mathrm{AlK}_{\alpha}$ source. Energy references are set using the HOPG C1s core level at $284.6 \mathrm{eV}$.

\section{Results}

\subsection{Preparation of Monocrystalline Ni Films and Carbon Implantation}

The Figure 2 displays one characteristic set of RHEED patterns recorded at different steps of the preparation process on Ni/MgO_5 sample. Previous RHEED observations highlight the importance to distinguish a germination step at a rather low temperature increasing the grain density from a growth step at higher temperature promoting the coarsening and the coalescence of the oriented grains. Moreover in agreement with literature [25] [31], an annealing step at higher temperature has been added after the growth step in order to improve the surface morphology.

In Figure 2(A) the RHEED pattern of $\mathrm{MgO}(111)$ substrate after in situ pretreatment at $1023 \mathrm{~K}$ displays rather wide bars. This broadening is likely due to some charge effects. This diagram is characteristic of a (111) surface without reconstruction, the bars displaying intensity modulations due to some surface roughness. Indeed the RMS of MgO(111) have been quoted to $1.6 \pm 0.1 \mathrm{~nm}$. The Figure 2(B) recorded after $100 \mathrm{~nm}$ Ni deposition at $635 \mathrm{~K}$ shows the RHEED diagram characteristics of an epitaxy of Ni on MgO(111) according to the orientation relationships $\mathrm{Ni}(111)[1 \overline{1} 0] / / \mathrm{MgO}(111)[1 \overline{1} 0]$. The form of the diagram undergoes only few evolutions, whereas the distance between the bars has increased. $\mathrm{Ni}$ and $\mathrm{MgO}$ have the same fcc structure, but with a different surface (111) lattice spacings of $0.249 \mathrm{~nm}$ and $0.298 \mathrm{~nm}$, respectively (Table 1). Taking as a reference the bar spacing of $\mathrm{MgO}(111)$ in Figure 2(A), one can evaluate the lattice parameter of the nickel deposited, from the interval distance between the bars, at $0.353 \mathrm{~nm}$, a value close with $0.35239 \mathrm{~nm}$ expected for bulk nickel. The difference is beyond $1 \%$ and may be attributed to the uncertainty of the measurements. Furthermore the intensity modulations of the bars are due to the nature of the growth which is of 3D type with the germination of oriented dots. Subsequent $300 \mathrm{~nm}$ growth at 873K shows less intensity modulations of the RHEED bars (Figure 2(C)), as the Ni islands become larger and coalesce. The accuracy of the RHEED patterns however is limited. There- 


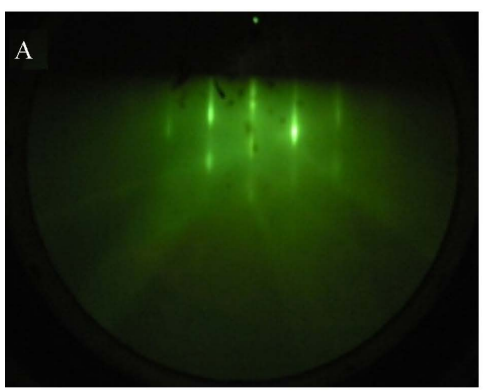

$\mathrm{D}$

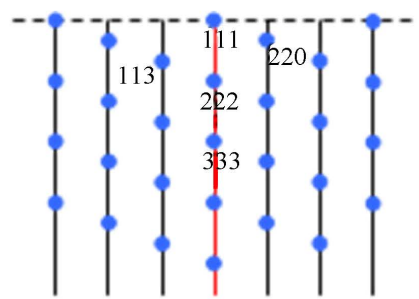

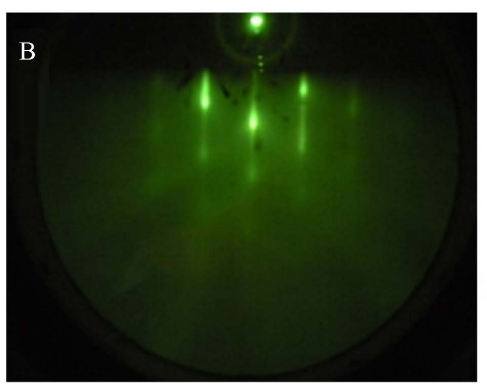

$\mathrm{E}$

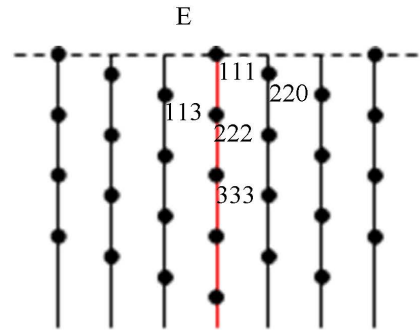

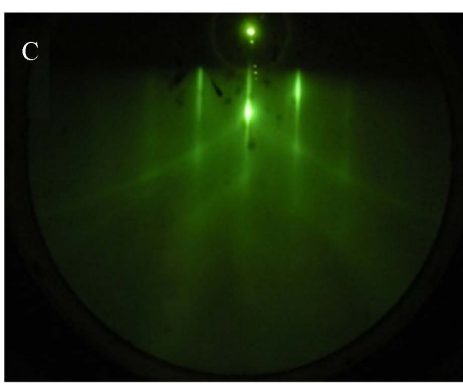

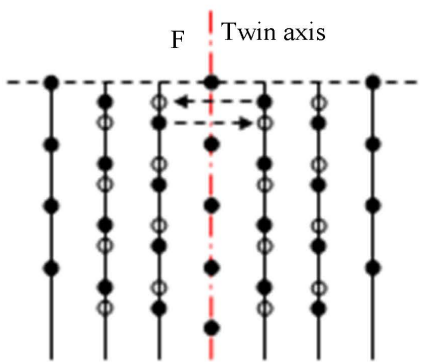

Figure 2. RHEED patterns during the growth of Ni/MgO_5 sample. (A) After in situ MgO(111) substrate pretreatment; (B) After $100 \mathrm{~nm}$ germination at $633 \mathrm{~K}$; and (C) Subsequent $300 \mathrm{~nm}$ growth at $873 \mathrm{~K}$. Beyond the RHEED patterns are displayed the expected RHEED diagrams of dots for a cfc structure along the azimuth $[1 \overline{10}]$ for (D)

$\mathrm{MgO}(111)$; (E) A single <111> oriented Ni film; (F) the same with the two twin orientations, one turned by $180^{\circ}$ from the other around [111].

fore the 3D diffraction cannot clearly distinguish the twin formation, i.e. whether a single or a two-domain $<111>$ oriented film is formed corresponding to the ABC or the ACB stacking modes, each of them turned by $180^{\circ}$ from the other one around [111], respectively. One illustration of these growth modes is displayed in Supplementary Material 2 (SM2).

The Figure 3(A), Figure 3(B) and Figure 3(D)-(F) show the SEM and AFM images of samples Ni/MgO_3-5, respectively. These samples are obtained with different temperatures of ultimate growth or post-treatment at 635 K (Figure 3(A), Figure 3(D)), 873 K (Figure 3(B), Figure 3(E)) and $1023 \mathrm{~K}$ (Figure 3(C), Figure 3(F)), respectively. After deposition at $635 \mathrm{~K}$ it can be seen that small grains of some $\mu \mathrm{m}^{2}$ size are not fully coalesced with the presence of dark pit sat boundaries, and also some protrusions whose origin is not known (Figure 3(A)). After subsequent growth at $873 \mathrm{~K}$ only few holes still exist as stitches, testifying that the coalescence is almost but not completely achieved (Figure 3(B)). After further annealing at $1015 \mathrm{~K}$ with a thicker film of $420 \mathrm{~nm}$ the holes have now completely disappeared and the morphology is now a film completely covering the surface, even if some roughness is apparent due to the plug of the remaining pits (Figure 3(C)). This is confirmed by the AFM images, as well as by the RMS measured on the surface of typical grains reported in Table 2. A high RMS is obtained on the sample Ni/MgO_1 due to the presence of large pits between the grains. We also note that the thickness is around $200 \mathrm{~nm}$ with the lowest deposition temperatures instead of $300 \mathrm{~nm}$ or more for the other samples. More AFM images on samples Ni/MgO_1-2 are displayed in Supplementary Material 3 (SM3).

The determination of the orientation of the nickel domains has been achieved by EBSD with an indexed diffraction figure (Figure 4(C)). The Figure 4(B) displays the pole figures obtained on a $300 \mathrm{~nm}$ Ni film deposited at $635 \mathrm{~K}$ with one single orientation by contrast with the growth performed at $605 \mathrm{~K}$ (Figure 4(A)). Then the double orientation within a $180^{\circ}$ rotation around the 111 pole normal to the surface is present with similar intensities. This is rather in good agreement with the literature data that state that a transition between a two-domain to a single domain nickel film occurs between $473 \mathrm{~K}$ and $573 \mathrm{~K}$ [25]. The reasons for this transition are not completely clear but are probably due to long range interactions between the first $\mathrm{Ni}$ layer and $\mathrm{MgO}$ subshells that promote favorable orientation of the nuclei [31].

The true thicknesses of the metallic films have been determined by RBS (Table 2). The Figure 5 shows typical RBS spectra recorded on the Ni/MgO_1 sample, one set in Figure 5(A) before (black) and after (red) carbon implantation, and another set in Figure 5(B) after carbon implantation in the channeling mode (black) and in the random mode (red), respectively. In addition to $\mathrm{Ni}, \mathrm{Mg}$ and $\mathrm{O}$ are also detected. The surface and interface 

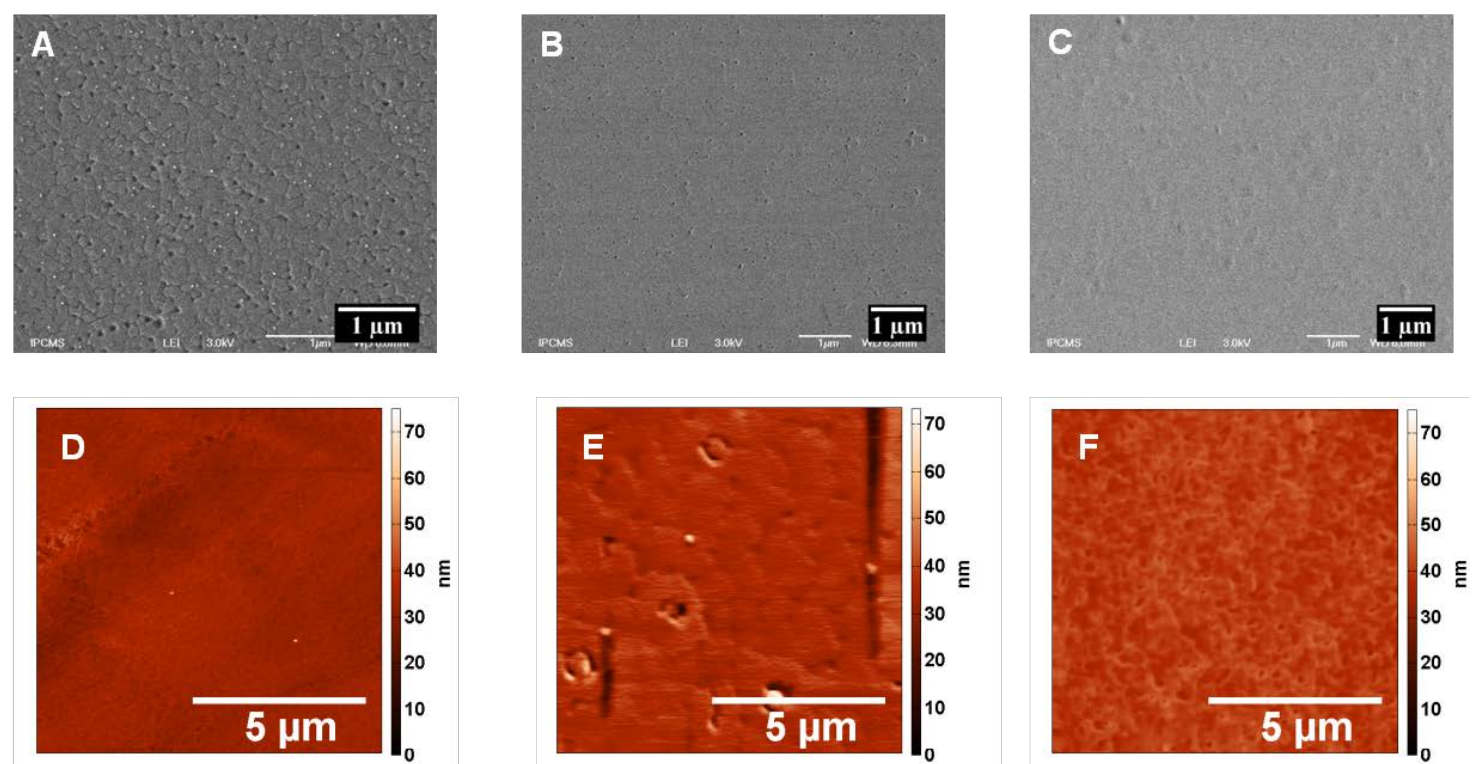

Figure 3. SEM and AFM images of the Ni/MgO_3 sample ((A) and (D)); Ni/MgO_4 sample ((B) and (E)); $\mathrm{Ni} / \mathrm{MgO} 55$ sample ((C) and (F)), respectively. The AFM and SEM scales are identical.
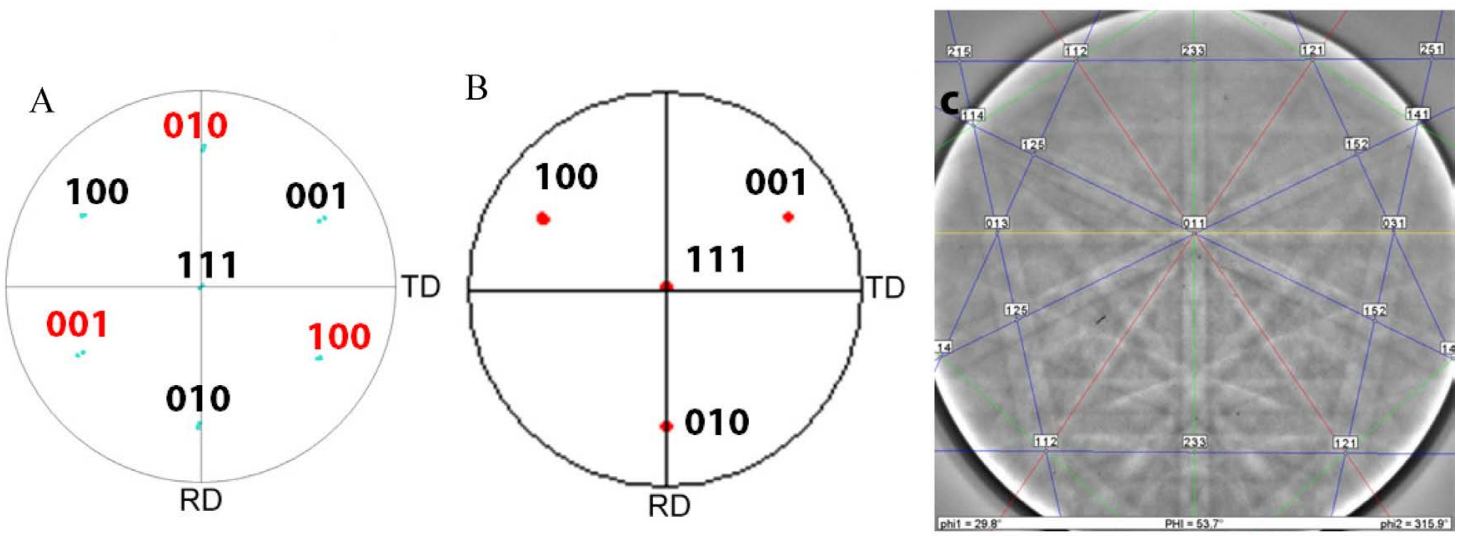

Figure 4. EBSD pole figures, with more than 200 points, of (A) a nickel film deposited at605 K (sample Ni/MgO_2); (B) a nickel film deposited at $635 \mathrm{~K}$ (sample Ni/MgO_3) displaying two and one single orientation, respectively; (C) Indexed EBSD of sample Ni/MgO_3.

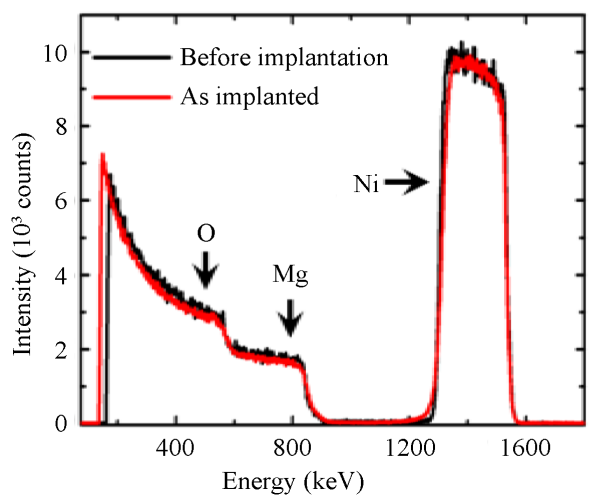

(A)

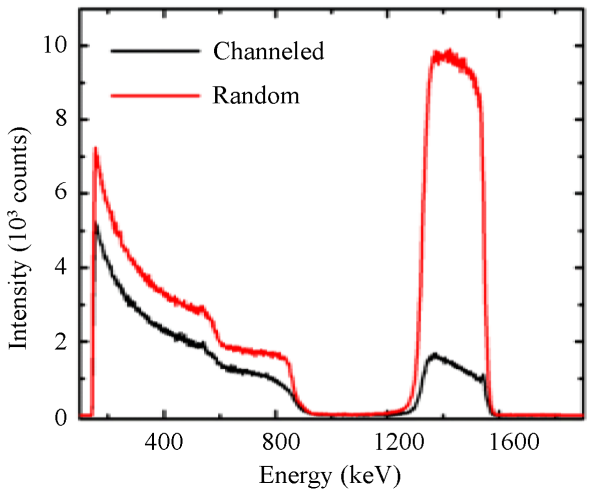

(B)

Figure 5. RBS spectra for the Ni/MgO_1 sample with a $9 \mu \mathrm{C}$ electron charge (A) before (black) and after (red) implantation, (B) in the random (red) and channeling (black) modes on the implanted sample, respectively. 
levels are rather steep before and after carbon implantation with an energy range $\Delta \mathrm{E}_{\mathrm{Ni}}$ corresponding to $186 \mathrm{~nm}$ in both cases. This reveals that the effect of surface Ni sputtering by implantation of carbon ions is negligible. When the beam of $\alpha$-particles is channeled along the [111] direction, the beam is much less backscattered as indicated by the notable decrease of the RBS signal of nickel in the channeling mode. The small signal, around $15 \%$ of the random signal, is relied therefore to defects in the Ni monocrystalline array due to local backscattering. This signal increases along the deepness of the Ni film with a crystallinity factor estimated as $1-\left(I_{\text {channel }} / I_{\text {random }}\right) \approx 87 \% \pm 2 \%$ where $I_{\text {channel }}$ and $I_{\text {random }}$ are the RBS intensities in the channeling and in the random modes at a given deepness, respectively. This result strongly confirms the good crystallization and the [111] orientation of the Ni films. The thicknesses of the Ni films determined by RBS reported in Table 2 are in rather good agreement with the measured ones by quartz microbalance.

\subsection{Graphene Formation through Carbon Implantation and Surface Diffusion}

Previous works [23] have shown that many carbon impurities are incorporated into the Ni films during the Ni growth as well as during the carbon implantation process, leading to an excess of carbon. To disentangle between the true carbon coming from the implantation process and the pollution carbon incorporated at any step of the process, we have used the ${ }^{13} \mathrm{C}$ isotope, which is only $1.07 \%$ of natural carbon.

Figure 6 shows the near-gaussian profile of the ${ }^{13} \mathrm{C}$ distribution after implantation at 20 and $50 \mathrm{keV}$ simulated by SRIM software. At these energies the carbon is implanted only into the nickel film whose thickness is at least $185 \mathrm{~nm}$. The mean implantation depths (projected ranges $\mathrm{R}_{\mathrm{p}}$ ) are $24 \mathrm{~nm}$ and $58 \mathrm{~nm}$ and the longitudinal straggles $\left(\Delta \mathrm{R}_{\mathrm{p}}\right.$, almost half width at half maxima) are 19 and $37 \mathrm{~nm}$ for carbon implantation energy of $20 \mathrm{keV}$ and $50 \mathrm{keV}$, respectively.

The ${ }^{13} \mathrm{C}$ isotope with a fluence of $1.4 \times 10^{16}$ at $/ \mathrm{cm}^{2}$ corresponding to 4 EGM have been implanted at $873 \mathrm{~K}$ and room temperature. The implantation at a high temperature induces concomitantly carbon atoms diffusion into the nickel film. As the carbon solubility in Ni decreases when temperature is decreasing the carbon atoms segregate towards the surface also when cooling after the implantation. The diffusion towards the interface $\mathrm{Ni} / \mathrm{MgO}$ is unlikely considering the projected ranges and the longitudinal straggles used (Figure 6).

The Figures 7(A)-(C) display SEM images of the samples Ni/MgO_2-4 after carbon implantation, respectively. At low thickness corresponding to sample Ni/MgO_1, the nickel film is not stable during carbon implantation (see Supplementary Material 4 (SM4)). However an evolution of the morphology with the thickness of the film and the implantation energy can be noted. On samples Ni/MgO_2 and Ni/MgO_3 the implantation energy is the same (20 keV), but the thickness of the Ni film is changing from 275 to $325 \mathrm{~nm}$. Dark fragments corresponding to TLG with sizes $\leq 2 \mu \mathrm{m}^{2}$ are located mainly around grain boundaries and are not very well-defined. On both samples TLG fragments are mainly relied to the presence of grain boundaries and other point defects, as for polycrystalline Ni films [23]. Preferential nucleation occurs due to preferential carbon diffusion along these grain boundaries or defects. Their presence could be related to an uncompleted coalescence of the oriented nickel particles at around $300 \mathrm{~nm}$ thick, but also to the damages created by the implantation process, especially at rather low implantation energy of $20 \mathrm{keV}$. As seen in the simulation profile of Figure 6 a large amount of carbon is let at the surface at low implantation energy, creating nucleation centers for further growth of TLG from carbon implanted into the bulk diffusing to the surface. Contrasts in the TLG fragments are due to variations of the thickness of the graphitic layers.

By contrast on sample Ni/MgO_4, prepared with implantation energy of $50 \mathrm{keV}$ with similar thickness, the surface sample is relatively seamless with no preferential location of the TLG fragments (Figure 7(C)). The germination density is far less dense, and the TLG fragments exhibit now clear 6-fold symmetry with size up to 5 $\mu \mathrm{m}^{2}$. The edge facets exhibit angles multiple of $60^{\circ}$, corresponding to the hexagonal graphite structure. Again some grey level contrasts suggest thickness variations, even inside a single fragment. On Ni/MgO_4-6 samples, the TLG are larger and better facetted than TLG grown on polycrystalline $\mathrm{Ni} / \mathrm{SiO}_{2}$ samples (see Figure $\mathrm{D}$ of Supplementary Material 4).

The AFM images (Figure 7(E), Figure 7(F)) confirm the increase of the grain sizes and the roughness on the surface of a Ni grain. Thus RMS of $3.9 \mathrm{~nm}$ and $6.2 \mathrm{~nm}$ are measured after implantation on Ni/MgO_4 and Ni/MgO_3 samples, respectively, instead of $3.1 \mathrm{~nm}$ and $2.4 \mathrm{~nm}$ before implantation, respectively. The overall roughness generally increases with the carbon implantation at $873 \mathrm{~K}$ (Table 2). Many physical phenomena occurring during heated implantation can explain this behavior: 1) diffusion of activated $\mathrm{Ni}$ atoms that promotes a 


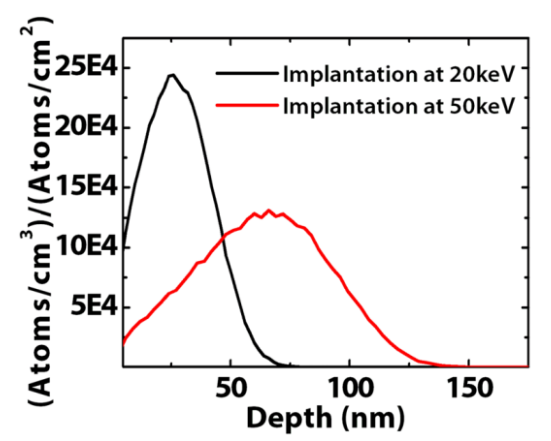

Figure 6. SRIM simulation of the implanted ${ }^{13} \mathrm{C}$ concentration profile at $20 \mathrm{keV}$ (black) and $50 \mathrm{keV}$ (red), corresponding to projected ranges $R_{p}$ of 24 and $58 \mathrm{~nm}$ and longitudinal straggles $\Delta R_{p}$ of 19 and $37 \mathrm{~nm}$, respectively.
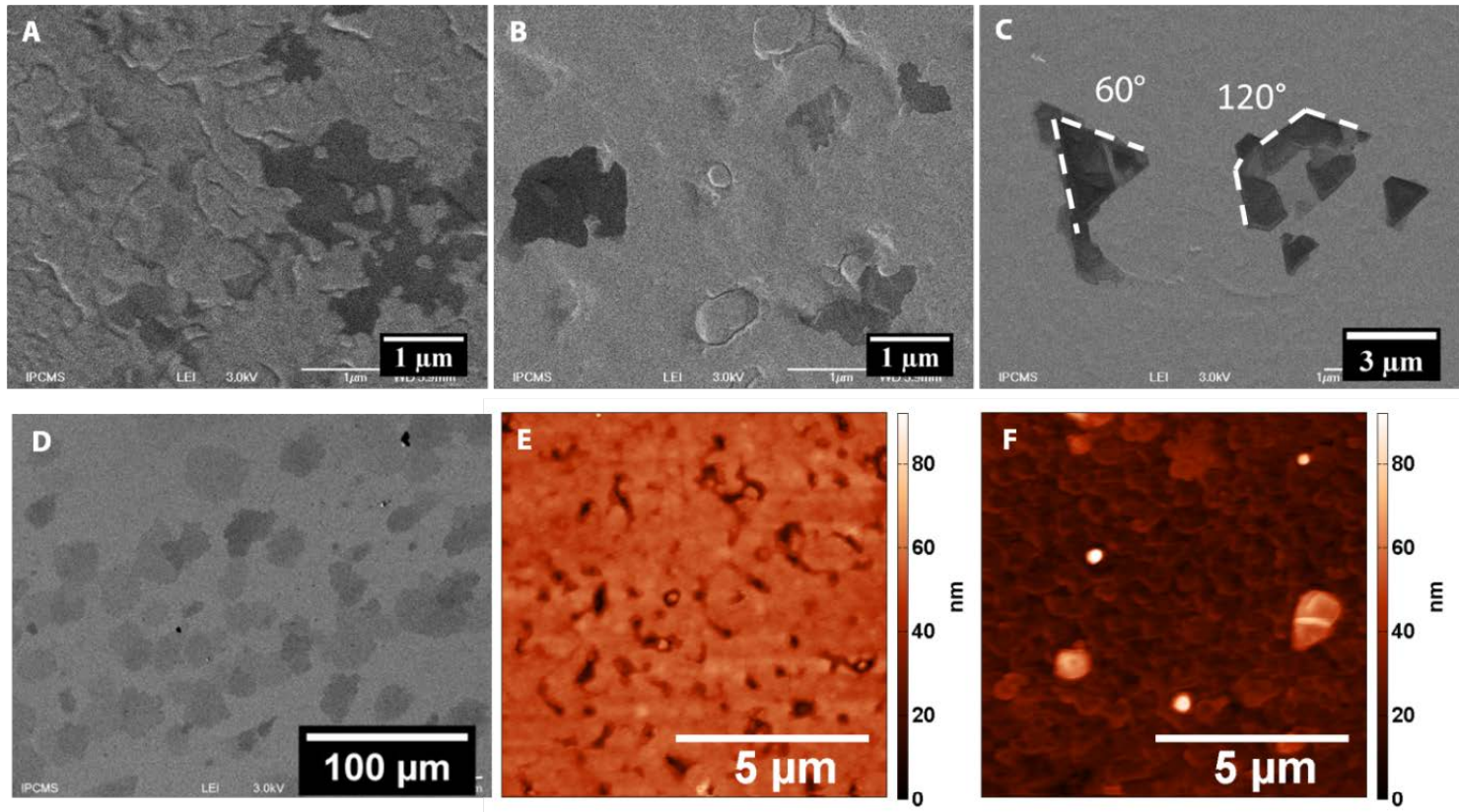

Figure 7. SEM images with a SEI detector at $3 \mathrm{kV}$ of samples: (A) Ni/MgO_2 and (B) Ni/MgO_3, both after carbon implantation at $873 \mathrm{~K}$ (20 keV energy); (C) Ni/MgO_4 after carbon implantation at $873 \mathrm{~K}$ (50 keV energy) and (D) $\mathrm{Ni} / \mathrm{MgO} \_6$ after annealing at $1173 \mathrm{~K}$. Note that the scale bar on sample Ni/MgO_4 is thrice the ones on other samples. AFM images of the (E) Ni/MgO_3 and (F) Ni/MgO_4 samples after implantation.

restructuration of the Ni grain surface but also a separation between the grains not completely coalesced; 2) creation of defects by sputtering of the surface with impinging carbon atoms. However the absence of any RMS change on Ni/MgO_6 sample, after carbon implantation but before heat treatment at $1173 \mathrm{~K}$, indicates that $\mathrm{Ni}$ sputtering by ion implantation can be neglected. The TLG fragments density strongly decrease with the TLG mean area (see Supplementary Material 5 in the case of Ni/MgO_3 sample), suggesting a unique and fast pathway of carbon diffusion inside Ni films.

The polar figure of the Ni films determined by EBSD (see Supplementary Material 6 (SM 6) completed with SEM images) before and after the carbon implantation reveals no modification on the crystallographic orientation, even if the surface are more disturbed after carbon implantation.

The NRA experiments have been performed at each step of the overall process described in Figure 1 in order to determine the origin of ${ }^{12} \mathrm{C}$ carbon impurities in addition to the implanted carbon ${ }^{13} \mathrm{C}$, the concentration and the localization of carbon inside Ni films. The Figure 8(A) shows NRA spectra in the random mode obtained on $\mathrm{Ni} / \mathrm{MgO}_{-} 1$ sample before and after the ${ }^{13} \mathrm{C}$ implantation at $873 \mathrm{~K}$ with a fluence of $4 \mathrm{EGM}$. The ${ }^{16} \mathrm{Op}_{0},{ }^{16} \mathrm{Op}_{1}$, ${ }^{12} \mathrm{Cp}$ and ${ }^{13} \mathrm{Cp}$ signals at $1140 \mathrm{keV}, 1970 \mathrm{keV}, 2760 \mathrm{keV}$ et $5740 \mathrm{keV}$ are due to the nuclear reactions ${ }^{16} \mathrm{O}(\mathrm{d}$, $\left.\mathrm{p}_{0}\right)^{17} \mathrm{O},{ }^{16} \mathrm{O}\left(\mathrm{d}, \mathrm{p}_{1}\right){ }^{17} \mathrm{O},{ }^{12} \mathrm{C}\left(\mathrm{d}, \mathrm{p}_{0}\right){ }^{13} \mathrm{C}$ and ${ }^{13} \mathrm{C}\left(\mathrm{d}, \mathrm{p}_{0}\right){ }^{14} \mathrm{C}$, respectively. The NRAs involving oxygen are included to 
ascertain the stability of the data collection, as the oxygen concentration is assumed unchanged by the implantation. The results are summarized in Table 3 where the carbon concentrations determined with the software SIMNRA are given in EGM. It can be seen that ${ }^{12} \mathrm{C}$ is incorporated into the film both during the nickel deposition (black curve of the ${ }^{12} \mathrm{C}\left(\mathrm{d}, \mathrm{p}_{0}\right){ }^{13} \mathrm{C}$ inset) as well as during the implantation itself (red curve of the ${ }^{12} \mathrm{C}(\mathrm{d}$, $\left.\mathrm{p}_{0}\right)^{13} \mathrm{C}$ inset). This has been already shown with polycrystalline nickel films evaporated on $\mathrm{SiO}_{2} / \mathrm{Si}$ [23]. The raw signals must be corrected by the NRA cross-sections which are $25.9 \mathrm{mb} / \mathrm{sr}$ [32] and $2.36 \mathrm{mb} / \mathrm{sr}$ [33] for ${ }^{12} \mathrm{C}(\mathrm{d}$, $p)^{13} \mathrm{C}$ and ${ }^{13} \mathrm{C}(\mathrm{d}, \mathrm{p}){ }^{14} \mathrm{C}$ reactions, respectively. Thus the error bars are estimated to around 1 and $2 \mathrm{EGM}$, respectively. Moreover we are not able to differentiate between the carbon surface and the carbon diluted into the Ni layer, as NRA is a bulk-sensitive technique. Within these limitations, it can be inferred from the results of Table 3 that:

1) The overall ${ }^{13} \mathrm{C}$ concentration is in the range $20 \%$ - $25 \%$ of the overall carbon concentration.

2) ${ }^{12} \mathrm{C}$ incorporation as impurity occurs both during the Ni sample preparation, and mainly during the ${ }^{13} \mathrm{C}$ implantation. This is bulk pollution inside the nickel film as Raman investigations fail to evidence any carbon signal on the Ni surface before the annealing at $873 \mathrm{~K}$.

The incorporation of ${ }^{12} \mathrm{C}$ has been discussed in greater details elsewhere [23].

In addition we have determined by NRA in the channeling mode the localization of each carbon isotope into the metallic matrix (Figure 8(B)). In both cases the NRA signal due to carbon remains unchanged. This infers that the carbon is randomly located outside the channels of the [111] direction, rather than in interstitial sites of the Ni cfc structure.

\subsection{Raman Spectroscopy}

The Figure 9(C), Figure 9(D), Figure 9(H), Figure 9(I) and Figure 9(M), Figure 9(N) show the Raman mappings of the $\mathrm{G}$ and 2D bands on the Ni/MgO_3, Ni/MgO_4 and Ni/MgO_6 samples, recorded in the 1100 - 1750 $\mathrm{cm}^{-1}$ and $2695-2800 \mathrm{~cm}^{-1}$ ranges, respectively. The mappings are recorded on an area of $10 \mu \mathrm{m}^{2}$ with an increasing intensity scale from dark to bright. Moreover, to illustrate the chemical contrast between the dark and the bright zones observed on the optical images of Figure 9(A), Figure 9(F) and Figure 9(K), several individual Raman spectra are displayed on Figure 9(B), Figure 9(G) and Figure 9(L), respectively.

Similar results have been obtained on Ni/MgO_1, Ni/MgO_2 and Ni/MgO_5 samples. The optical images (Figure 9(A), Figure 9(F) and Figure 9(K)) show dark TLG fragments formed during implantation/surface segregation. The contrast is however weaker in Figure 9(K) of Ni/MgO_6 sample. These TLG fragments display variable sizes, up to $4 \mu \mathrm{m}^{2}$ for sample Ni/MgO_3 and up to $10 \mu \mathrm{m}^{2}$ for sample Ni/MgO_4, but more than 100 $\mu \mathrm{m}^{2}$ on Ni/MgO_6 sample. Corresponding typical Raman spectra (Figure 9(B), Figure 9(G) and Figure 9(L)) are collected on the edge or inside the TLG fragments at locations labelled in the images (Figure 9(A), Figure 9(F) and Figure 9(K), respectively). As expected the Raman spectra exhibit a G band at around 1565 - 1580 $\mathrm{cm}^{-1}$ and 2D band at around $2670-2700 \mathrm{~cm}^{-1}$. The G band is the one-mode Raman vibration characteristic of graphitic carbon [34]. The 2D band is a multiple step mode of carbon vibration whose intensity, shape and wave

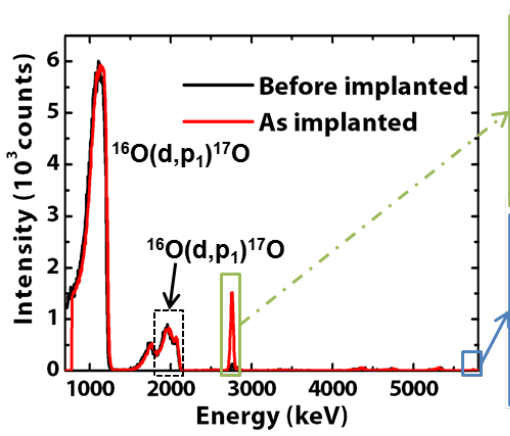

(A)

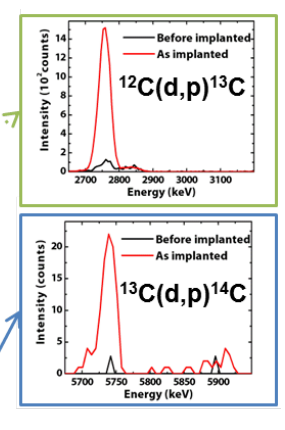

ed with a

with a deutons beam $\left(\mathrm{D}^{+}\right)$at $900 \mathrm{keV}$ on $(\mathrm{A}) \mathrm{Ni} / \mathrm{MgO} \_1$ sample before (black) and after (red) ${ }^{13} \mathrm{C}$ implantation at $873 \mathrm{~K}$; (B) in the random (red) and in the channeling (black) mode, respectively. The reactions ${ }^{12} \mathrm{C}(\mathrm{d}, \mathrm{p} 0){ }^{13} \mathrm{C}$ and ${ }^{13} \mathrm{C}(\mathrm{d}, \mathrm{p} 0)^{14} \mathrm{C}$ are zoomed in the green (top) and blue (bottom) insets, respectively. We can note the evolution of the oxygen signal in the channeling mode likely due to the epitaxial relationship with $\mathrm{Ni}(111)$. 
Table $3 .{ }^{12} \mathrm{C}$ and ${ }^{13} \mathrm{C}$ concentrations before and after implantation (in EGM) obtained from experimental NRA intensities fitted with SIMNRA.

\begin{tabular}{ccccc}
\hline \multirow{2}{*}{ Sample } & & ${ }^{12} \mathrm{C}($ EGM) Error \pm 1 & ${ }^{13} \mathrm{C}($ EGM) Error \pm 2 & Overall ${ }^{12} \mathrm{C}+{ }^{13} \mathrm{C}$ \\
\hline \multirow{2}{*}{ Ni/MgO_1 } & Before & 4 & 0 & 4 \\
& After & 10 & 2.8 & 12.8 \\
Ni/MgO_2 & Before & 3 & 0 & 3 \\
& After & 11 & 2.4 & 13.4 \\
Ni/MgO_3 & Before & 5.3 & 0 & 5.3 \\
& After & 9.9 & 3.3 & 13.2 \\
Ni/MgO_4 & Before & 4.5 & 0 & 4.5 \\
& After & 10.1 & 3.2 & 13.3 \\
Ni/MgO_5 & Before & 4.9 & 0 & 4.9 \\
& After & 12 & 3.4 & 15.4 \\
Ni/MgO_6 & Before & - & 0 & - \\
& After & 7.9 & 3.3 & 11.2 \\
\hline
\end{tabular}
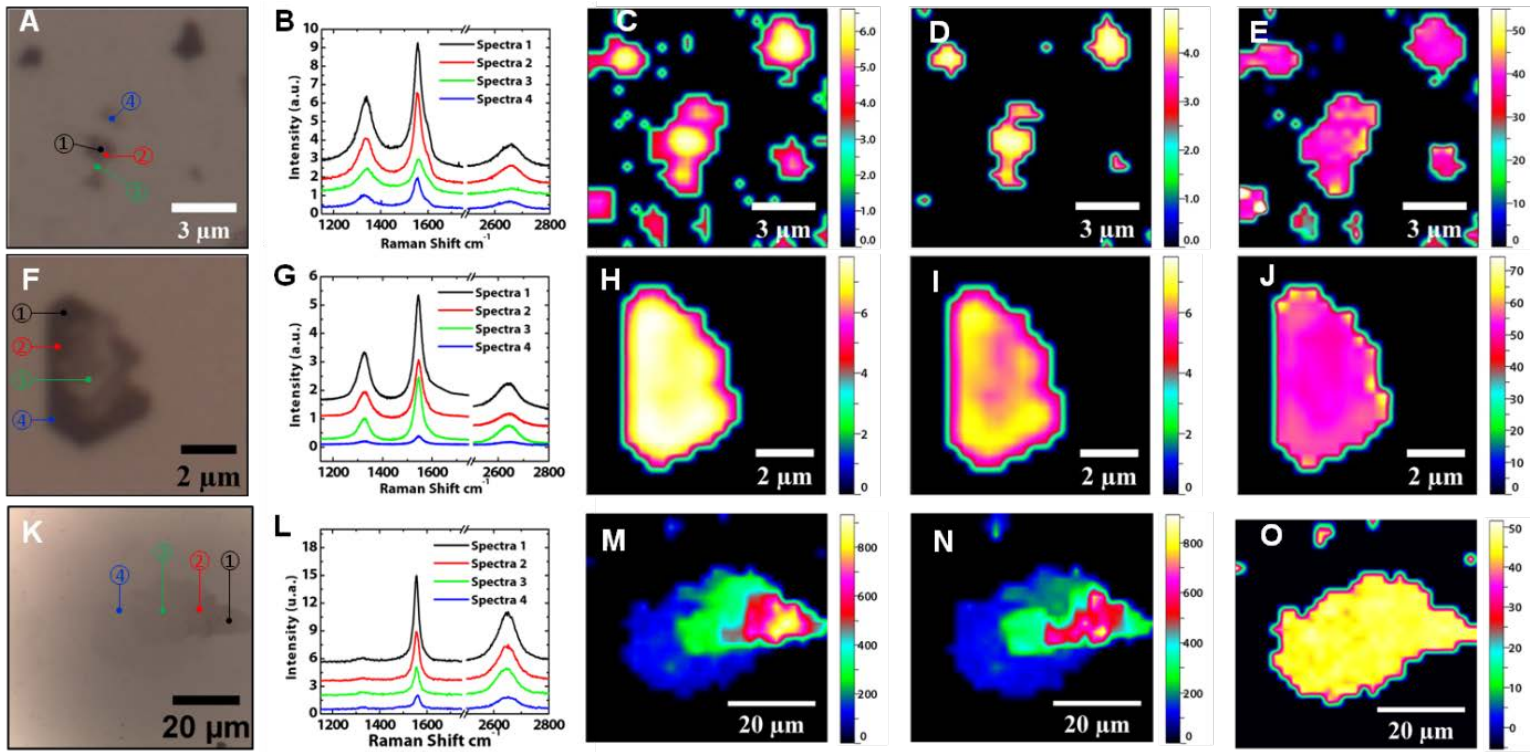

Figure 9. (A) (F) (K) Optical images; (B) (G) (L) individual Raman spectra labelled on the images (A) (F) (K) with the same color code, respectively; (C) (H) (M) Raman mappings of the G band; (D) (I) (M) Raman mappings of the 2D band; (E) (J) (O) Raman mappings of the ${ }^{13} \mathrm{C}$ concentration according to Equation (1) taken from the downshift of the $\mathrm{G}$ band. Ni/MgO_3 (A)-(E), Ni/MgO_4 (F)-(J) and Ni/MgO_6 (K)-(O) samples, respectively.

number are sensitive to the interaction with the substrate, to the thickness of the graphene layers, to the ordering within the graphene layers in the direction c normal to the graphene planes and to the presence of either impurities or doping atoms, or vacancies, or functionalized molecules [35]. The detection of such 2D band is a strong indication that the ordering of the graphene planes starts to occur. Furthermore as soon as graphitic domains display either structural defects or size-limited dimensions a D band at around $1360 \mathrm{~cm}^{-1}$ will appear [36]. Finally on sample Ni-MgO_3 a D' band around $1615-1620 \mathrm{~cm}^{-1}$ as a shoulder of the G band can be seen that is due to rolling, wrapping or rippling of the TLG sheet. Contrasts from different fragments or within the same TLG fragment are probably due to variable thickness as indicated by the variable intensity of the $\mathrm{G}$ band (Figure 9 (F), Figure 9(G) and Figure 9(K), Figure 9(L) for Ni/MgO_4 and Ni/MgO_6 samples, respectively).

The mappings show rather steady intensity of the $G$ and $2 \mathrm{D}$ bands on the large TLG fragment of the 
Ni/MgO_4 sample, while the distribution is more variable with the small TLG fragments of the Ni/MgO_3 sample and on the large TLG fragment of Ni/MgO_6 sample.

Some other Raman characteristics of the Ni/MgO_X samples are reported in Table 4. The strong intensity of the $2 \mathrm{D}$ band on $\mathrm{Ni} / \mathrm{MgO}(111) \_6$ sample, as well as the narrowing of all the $\mathrm{D}, \mathrm{G}$ and 2D bands, compared to any other $\mathrm{Ni} / \mathrm{MgO}$ sample confirm an ordering of the graphene plans in the c direction and an advanced graphitization due to the high pretreatment temperature. The ratio $\mathrm{I}_{\mathrm{D}} / \mathrm{I}_{\mathrm{G}}$ is sensitive to the structural disorder as well as the size limitations of the films [37]. Among samples implanted at high temperatures, the ratio $\mathrm{I}_{2 \mathrm{D}} / \mathrm{I}_{\mathrm{G}}$ is increasing with Ni/MgO_4 sample, whereas the Full Widths at Half maximum (FWHM) of G and 2D bands are decreasing, as expected from a better ordering of the graphene layers.

On Figure 9(E), Figure 9(J) and Figure 9(O) Raman mappings of the ${ }^{13} \mathrm{C}$ concentration on TLG fragments are displayed. The ${ }^{13} \mathrm{C}$ concentrations $\mathrm{c}$ are calculated from the downshift of the $\mathrm{G}$ band wavenumber $\Delta \omega_{i}$ according to Equation (1), assuming random isotope distribution and equal bond force constants [38]:

$$
\Delta \omega(\mathrm{G})=\left(\omega_{0}-\omega\right)(\mathrm{G})=\omega_{0}(\mathrm{G})\left(1-\sqrt{\frac{\left(12+\mathrm{C}_{0}\right)}{(12+\mathrm{C})}}\right)
$$

where $\omega_{0}$ is the frequency of the given Raman mode $\mathrm{G}$ in the ${ }^{12} \mathrm{C}$ implanted sample $\left(\omega_{0}(\mathrm{G})=1581 \mathrm{~cm}^{-1}\right), \mathrm{C}_{0}$ is the ${ }^{13} \mathrm{C}$ concentration in the ${ }^{12} \mathrm{C}$ samples $\left({ }^{13} \mathrm{C}\right.$ natural abundance $\left.=0.0107\right)$. The isotopic distributions are rather uniform on a single fragment, around $30 \%-40 \%, 40 \%-50 \%$, and $40 \%-50 \%$ on Ni/MgO_3, Ni/MgO_4 and $\mathrm{Ni} / \mathrm{MgO} 6$ samples, respectively. Thus the ${ }^{13} \mathrm{C}$ concentrations determined by Raman spectroscopy are stronger than the ${ }^{13} \mathrm{C}$ concentrations determined by NRA (Table 3). However it should be reminded that the later probe is both a bulk- and surface-sensitive probe, whereas the former one is only a surface-sensitive probe. Moreover the downshift of the 2D or G wavelengths can also be sensitive to other parameters, such as the thickness of the graphitic fragment, the occurrence of either impurities, or doping, or vacancies or functionalized adsorbents. However these last effects infer rather weak amplitude of the shift compared to the ${ }^{13} \mathrm{C}$ isotopic effect, so that the main conclusions may be still valid.

Finally we have estimated the mean thickness of surface carbon concentration by angular XPS measurements on the Ni/MgO_3 sample (Figure 10). The XPS carbon signal C1s obtained on this signal $I_{\text {Gene }}$ is continuously recorded along with the C1s signal of the HOPG graphite $\mathrm{I}_{\text {Gite }}$ taken as reference.

Assuming that the mean free path of the inelastic process of carbon $\lambda_{C}$ is the same on both samples and that the surface is continuously covered by a carbon layer of thickness e, e can be extracted from the ratio $I_{\text {Gene }} / I_{\text {Gite }}$ of the C1s signal. Indeed $I_{\text {Gene }}$ can be expressed as [22]:

$$
I_{\text {Gene }}=A \cdot N_{\text {Gene }} \cdot \sigma_{\text {C1s }} \cdot \lambda_{\text {Gene }} \cdot \cos \theta\left[1-\exp \left(-e / \lambda_{C} \cdot \cos \theta\right)\right]
$$

where $\theta$ is the angle between the normal to the sample surface and the electron detector, $A$ is a constant geometric factor, $\sigma_{\mathrm{C} 1 \mathrm{~s}}$ is the C1s photoelectron cross section, $N_{\mathrm{Gene}}$ and $\lambda_{\text {Gene }}$ are the carbon atomic density and the mean free path of photoelectron in the graphene layers. On a HOPG reference, the C1s signal with infinite carbon layer $I_{\text {Gite }}$ is expressed as:

$$
I_{\text {Gite }}=A \cdot N_{\text {Gite }} \cdot s_{\text {C1s }} \cdot \lambda_{\text {Gite }} \cdot \cos \theta
$$

Taking the ratio $I_{\text {Gene }} / I_{\text {Gite }}$ from Equations (2) and (3) and assuming that the mean free path of the inelastic process on C1s level is around the same on both samples, ie $\lambda_{\text {Gite }} \approx \lambda_{\text {Gene }} \approx \lambda_{C}$, and the atomic densities are identical on graphene layers and graphite, ie $N_{\text {Gene }} \approx N_{\text {Gite }}$, the thickness e can be extracted by the following relation (4):

$$
\operatorname{Ln}\left\{1 /\left[1-\left(I_{\text {Gene }} / I_{\text {Gite }}\right)\right]\right\}=e / \lambda_{C} \cdot \cos \theta
$$

The mean thickness is thus extracted from the slope of the plot of Equation (4) (Figure 10(B)) by varying $\theta$ with $\lambda_{C}=2.1 \mathrm{~nm}$ [39]. The mean thickness extracted is quoted to $5 \pm 0.5 \mathrm{EGM}$. This value is in rather good agreement with the dose of implanted carbon (around 3.3 EGM), but lower than the measured amount of carbon by NRA estimated to 13.2 EGM (Table 3). However, we must remind that NRA encompasses both surface and bulk carbon. Therefore, it is presumed that carbon remains diluted into the Ni matrix, e.g. $(13.2-5) E G M=8.2$ EGM for Ni/MgO_3 sample. 
Table 4. Raman characteristics of Ni/MgO_X samples $(1 \leq \mathrm{X} \leq 6)$.

\begin{tabular}{cccccc}
\hline Sample & $\mathrm{I}_{\mathrm{D}} / \mathrm{I}_{\mathrm{G}}$ & $\mathrm{I}_{2 \mathrm{D}} / \mathrm{I}_{\mathrm{G}}$ & $\mathrm{FWHM}_{\mathrm{D}}\left(\mathrm{cm}^{-1}\right)$ & $\mathrm{FWHM}_{\mathrm{G}}\left(\mathrm{cm}^{-1}\right)$ & $\mathrm{FWHM}_{2 \mathrm{D}}\left(\mathrm{cm}^{-1}\right)$ \\
\hline Ni/MgO_1 & $0.70 \pm 0.1$ & $0.20 \pm 0.05$ & $80 \pm 5$ & $45 \pm 5$ & $115 \pm 15$ \\
Ni/MgO_2 & $0.80 \pm 0.1$ & $0.20 \pm 0.1$ & $75 \pm 10$ & $60 \pm 5$ & $100 \pm 15$ \\
Ni/MgO_3 & $0.40 \pm 0.1$ & $0.30 \pm 0.1$ & $80 \pm 10$ & $40 \pm 5$ & $105 \pm 10$ \\
Ni/MgO_4 & $0.35 \pm 0.1$ & $0.45 \pm 0.1$ & $70 \pm 10$ & $40 \pm 5$ & $100 \pm 10$ \\
Ni/MgO_5 & $0.75 \pm 0.1$ & $0.20 \pm 0.1$ & $80 \pm 10$ & $70 \pm 10$ & $100 \pm 10$ \\
Ni/MgO_6 & $0.12 \pm 0.1$ & $0.90 \pm 0.1$ & $55 \pm 10$ & $30 \pm 5$ & $80 \pm 10$ \\
\hline
\end{tabular}

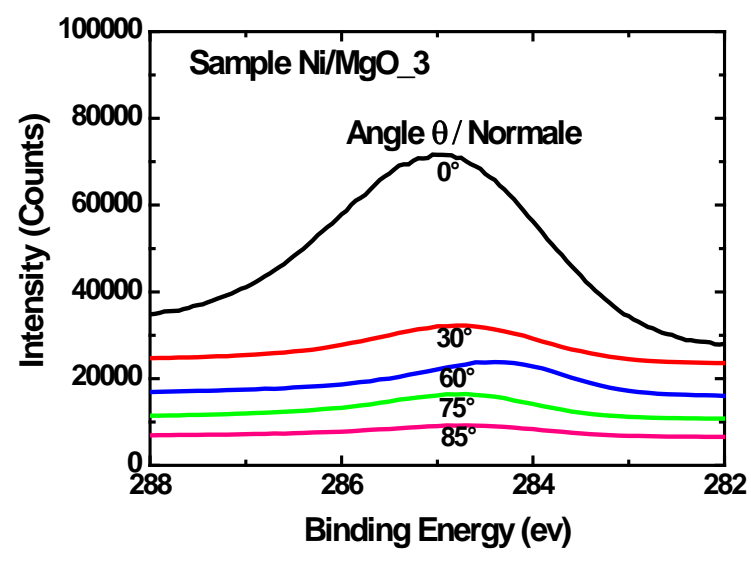

A

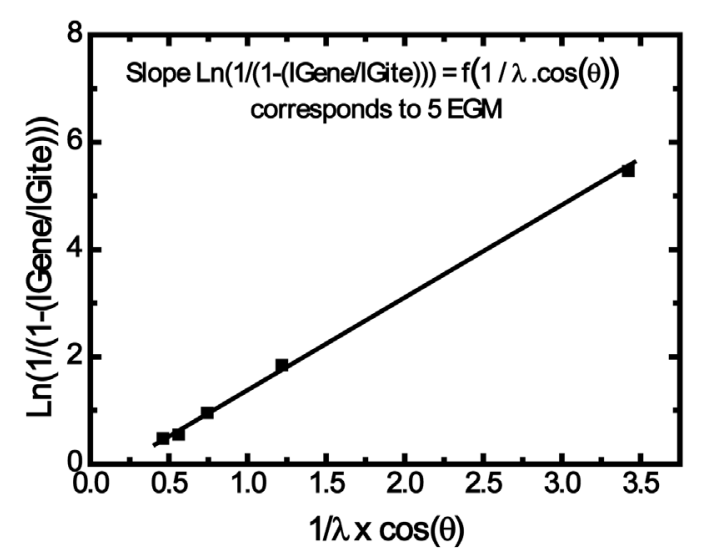

$\mathrm{B}$

Figure 10. (A) XPS intensity of the $\mathrm{C} 1 \mathrm{~s}$ core level at different angle $\theta$ on Ni/MgO_ 3 sample, normalized to the Cis core level intensity of HOPG; (B) Linear plot given the surface carbon concentration in EGM according to Equation (4).

\section{Discussion}

The carbon surface segregation from bulk Ni(111) and the carbon precipitation into a new phase (graphite) on the surface of Ni(111) has been studied earlier by the group of Blakely [40] [41]. They observed a segregation in one layer graphene (or carbon layer) that occurs before the phase transition to multilayer graphite by precipitation from the bulk carbon reservoir or by condensation from a carbon precursor of the gas phase. Therefore a stable domain of temperature for the formation of one monolayer carbon does exist on $\mathrm{Ni}(111)$ surface, closely related to the bulk concentration of carbon into the Ni(111) films. Beyond the solubility line (up line in Figure 11) the carbon precipitates to graphite. Below the segregation line (down line in Figure 11), low submonolayer carbon coverage occurs.

We have evaluated this carbon bulk concentration $x=\mathrm{C} / \mathrm{Ni}$ (at/at) in our films from the bulk carbon concentration determined by NRA and the thickness of the Ni film determined by RBS, according to an expression developed in reference [22], Supplementary Material 4, and we have compared these values with the segregation and the solubility lines in an Arrhenius plot (Figure 11). Clearly it could be seen that the carbon concentration in the bulk is well above the solubility line at the highest temperature of treatment, which are $873 \mathrm{~K}$, the implantation temperature, for $\mathrm{Ni} / \mathrm{MgO} \mathrm{X}$ with $1 \leq \mathrm{X} \leq 4,1015 \mathrm{~K}$ and $1175 \mathrm{~K}$ for $\mathrm{X}=5$ and $\mathrm{X}=6$, respectively. Therefore the carbon would directly precipitate in the form of multilayer graphite on the basis of these thermodynamic considerations. This must be balanced with kinetics diffusion of this carbon to the surface however, but it is reported that the diffusion of carbon in nickel is fast at the temperatures considered here. So we believed we are not far from thermodynamic conditions at temperatures above around $823 \mathrm{~K}$. By contrast, if we consider only the expected carbon bulk concentration of 4 EGM obtained by implantation it can be seen that this concentration fills in the domain of monolayer formation at the highest temperature treatment of $1175 \mathrm{~K}$ and is slightly larger at lower temperature treatments. The results reported in Table 3 show however that the carbon concentrations are even overestimated, but the error in the determination of the ${ }^{13} \mathrm{C}$ carbon is high. 


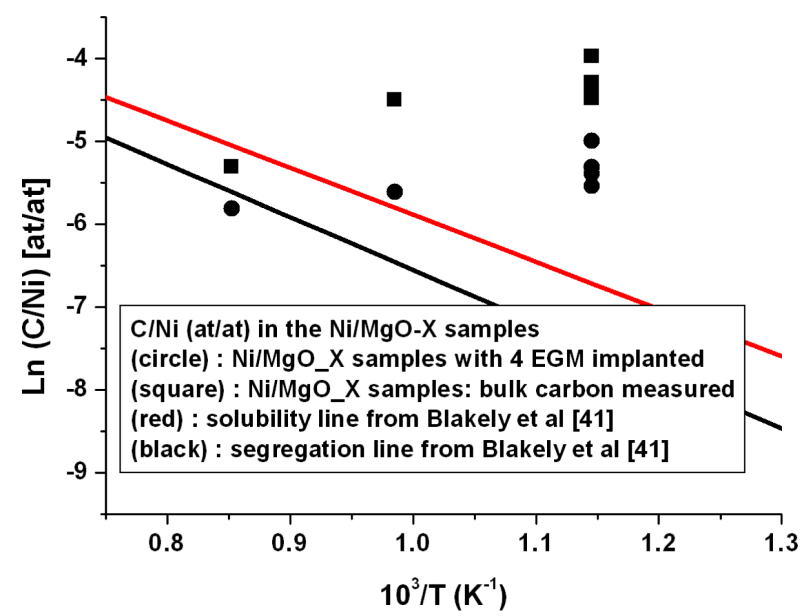

Figure 11. Arrhenius plot of the experimental $\mathrm{C} / \mathrm{Ni}$ bulk concentrations ratio (at/at) (square) in Ni/MgO_X samples; the expected C/Ni bulk concentration at 4EGM implantation ((circle); the solubility line (red line) and the segregation line (black line) of carbon from $\mathrm{Ni}(111)$ (from ref [41]).

Therefore the process suffer two main limitations:

- The non-controlled inclusion of ${ }^{12} \mathrm{C}$ at different steps of the process. This intrusion of carbon leads to a carbon supersaturation into the bulk nickel film.

- Due to carbon supersaturation mainly, and also to the occurrence of defects in nickel as well, a high nucleation rates is observed that leads to the formation of many fragments of variable size and thickness. Anyway these two factors prevent uniform nucleation.

Finally the same strategy could be used on $\mathrm{Cu}(111) / \mathrm{MgO}(111)$ films, as the copper is known to Incorporate very few amount of carbon [42].

\section{Conclusions}

The objectives of this study were the elaboration of graphene by carbon implantation at moderate temperature (873 K) in a monodomain epitaxilly-grown $\mathrm{Ni}(111)$ film deposited on a $\mathrm{MgO}(111)$ substrate. First monodomain (111) nickel films have been grown by molecular beam epitaxy. The growth has been monitored by RHEED. The films studied by EBSD, AFM and RBS in the channeling mode are well-oriented with good structural and alignment characteristics according to $\mathrm{Ni}(111)[1 \overline{1} 0] / / \mathrm{MgO}(111)[1 \overline{1} 0]$. Monocrystalline monodomains $\mathrm{Ni}(111)$ are obtained after germination at $635 \mathrm{~K}$, in rather good agreement with literature. Completion of the film is obtained after a growth step at $873 \mathrm{~K}$. Optimized conditions are successively: 1) a thermal post-treatment at 1023 $\mathrm{K}$; 2) a germination step at $633 \mathrm{~K}$; 3) a step growth at $873 \mathrm{~K}$ and finally 4) a post-annealing treatment at $1023 \mathrm{~K}$.

Then ${ }^{13} \mathrm{C}$ implantation into these nickel films is subsequently achieved at $873 \mathrm{~K}$ with energy within $20-50$ $\mathrm{keV}$ and a carbon dose equivalent to 4 monolayers of graphene $\left(1.4 \times 10^{16} \mathrm{at} / \mathrm{cm}^{2}\right)$. Major part of carbon directly diffuses towards the surface, forming TLGs of variable size and thickness. However these TLG are larger and better facetted than the TLG grown on a Ni polycrystalline film under similar conditions. The combined use of NRA, XPS and Raman allow to determine the global, surface and bulk concentrations of ${ }^{12} \mathrm{C}$ and ${ }^{13} \mathrm{C}$, the former being included in the Ni matrix at different steps of the process, mainly during the ${ }^{13} \mathrm{C}$ implantation itself. The results show that, in addition to implanted ${ }^{13} \mathrm{C},{ }^{12} \mathrm{C}$ is incorporated at different steps of the process and both isotopes are involved in the formation of the graphene monolayers.

The incorporation of carbon during the process, as well as the high level quality of the $\mathrm{Ni}(111)$ films are key parameters to control the graphene growth.

\section{Acknowledgements}

J. Faerber (IPCMS, Strasbourg) and Y. Le Gall (ICube/MaCEPV) are acknowledged for the SEM images and NRA measurements, respectively. 


\section{References}

[1] Avouris, P. and Dimitrakopoulos, C. (2012) Graphene: Synthesis and Applications. Materials Today, 15, 86-97. http://dx.doi.org/10.1016/S1369-7021(12)70044-5

[2] Fuhrer, M.S., Lau, C.N. and MacDonald, A.H. (2010) Graphene: Materially Better Carbon. Material Research Society Bulletin, 35, 289-295. http://dx.doi.org/10.1557/mrs2010.551

[3] Castro Neto, A.H., Peres, N.M.R., Guinea, F., Novoselov, K.S. and Geim, A.K. (2009) The Electronic Properties of Graphene. Review of Modern Physics, 81, 109-162. http://dx.doi.org/10.1103/RevModPhys.81.109

[4] Jang, W.Y., Chen, Z., Bao, W.Z., Lau Z.N. and Dames, C. (2010) Thickness-Dependent Thermal Conductivity of Encased Graphene and Ultrathin Graphite. Nano Letters, 10, 3909-3913. http://dx.doi.org/10.1021/nl101613u

[5] Lee, C.G., Wei, X.D., Kysar, J.W. and Home, J. (2008) Measurement of the Elastic Properties and Intrinsic Strength of Monolayer Graphene. Science, 321, 385-388. http://dx.doi.org/10.1126/science.1157996

[6] Blake, P., Hill, E.W., Castro Neto, A.H., Novoselov, K.S., Jiang, D., Yang, R., Booth, T.J. and Geim, A.K. (2007) Making Graphene Visible. Applied Physics Letters, 91, Article ID: 063124. http://dx.doi.org/10.1063/1.2768624

[7] Bolotin, K.I., Sikes, K.J., Jiang, Z., Klima, M., Fudenberg, G., Hone, J., Kim, P. and Stormer, H.L. (2008) Ultrahigh Electron Mobility in Suspended Graphene. Solid State Communications, 146, 351-355. http://dx.doi.org/10.1016/j.ssc.2008.02.024

[8] Gruneis, A., Kummer, K. and Vyalikh, D.V. (2009) Dynamics of Graphene Growth on a Metal Surface: A Time-Dependent Photoemission Study. New Journal of Physics, 11, Article ID: 073050. http://dx.doi.org/10.1088/1367-2630/11/7/073050

[9] Mattevi, C., Kim, H.K. and Chhowalla, M. (2011) A Review of Chemical Vapour Deposition of Graphene on Copper. Journal of Materials Chemistry, 21, 3324-3334. http://dx.doi.org/10.1039/C0JM02126A

[10] Han, G.H., Gunes, F., Bae, J.J., Kim, E.S., Chae, S.J., Shin, H.J., Choi, J.Y., Pribat, D. and Lee, Y.H. (2011) Influence of Copper Morphology in Forming Nucleation Seeds for Graphene Growth. Nano Letters, 11, 4144-4148. http://dx.doi.org/10.1021/nl201980p

[11] Yu, Q.K., Jauregui, L.A., Tian, J., Wu, W., Colby, R., Liu, Z.H., Su, Z., Cao, H., Jalilian, R., Pandey, D., Wei, D.G., Chung, T.F., Peng, P., Guisinger, N.P., Stach, E.A., Bao, J., Pei, S.S.S. and Chen, Y.P. (2011) Control, and Characterization of Individual Grains and Grain Boundaries in Graphene Grown by Chemical Vapour Deposition. Nature Materials, 10, 443-449. http://dx.doi.org/10.1038/nmat3010

[12] Iwasaki, T., Park, H.J., Konuma, M., Lee, D.S., Smet, J.H. and Starke, U. (2011) Long-Range Ordered Single-Crystal Graphene on High-Quality Heteroepitaxial Ni Thin Films Grown on MgO(111). Nano Letters, 11, 79-84. http://dx.doi.org/10.1021/nl102834q

[13] Reddy, K.M., Gledhill, A.D., Chen, C.H., Drexler, J.M. and Padture, N.P. (2011) High Quality, Transferrable Graphene Grown on Single Crystal Cu(111) Thin Films on Basal-Plane Sapphire. Applied Physics Letters, 98, 113117/1-3. http://dx.doi.org/10.1063/1.3569143

[14] Ogawa, Y., Hu, B., Orofeo, C.M., Tsuji, M., Mizuno, S., Ikeda, K.I., Hibino, H. and Ago, H. (2012) Domain Structure and Boundary in Single-Layer Graphene Grown on $\mathrm{Cu}(111)$ and $\mathrm{Cu}(100)$ Films. The Journal of Physical Chemistry Letters, 3, 219-226. http://dx.doi.org/10.1021/jz2015555

[15] Hu, B.S., Ago, H., Ito, Y., Kawahara, K., Tsuji, M., Magome, E., Sumitani, K., Mizuta, N., Ikeda, K.I. and Mizuno, S. (2012) Epitaxial Growth of Large-Area Single-Layer Graphene over Cu(111)/Sapphire by Atmospheric Pressure CVD. Carbon, 50, 57-65. http://dx.doi.org/10.1016/j.carbon.2011.08.002

[16] Garaj, S., Hubbard, W. and Golovchenko, J.A. (2010) Graphene Synthesis by Ion Implantation. Applied Physics Letters, 97, 183103-183106. http://dx.doi.org/10.1063/1.3507287

[17] Baraton, L., Maurice, J.L., Cojocaru, C.S., Pribat, D., He, Z.B., Lee, Y.H., Lee, C.S. and Gourgues-Lorenzon, A.F. (2011) Synthesis of Few-Layered Graphene by Ion Implantation of Carbon in Nickel Thin Films. Nanotechnology, 22, 085601-085606. http://dx.doi.org/10.1088/0957-4484/22/8/085601

[18] Mun, J.H., Lim, S.K. and Cho, B.J. (2012) Local Growth of Graphene by Ion Implantation of Carbon in a Nickel Thin Film Followed by Rapid Thermal Annealing. Journal of the Electrochemical Society, 159, G89-G92. http://dx.doi.org/10.1149/2.059206jes

[19] Zhang, R., Zhang, Z.D., Wang, Z.S., Wang, S.X., Wang, W., Fu, D.J. and Liu, J.R. (2012) Nonlinear Damage Effect in Graphene Synthesis by C-Cluster Ion Implantation. Applied Physics Letters, 101, 0119051-0119054. http://dx.doi.org/10.1063/1.4732088

[20] Zhang, Z.D., Wang, Z.S., Zhang, R., Wu, X.Y., Fu, D.J. and Liu, J.R. (2013) Improvement of Graphene Quality Synthesized by Cluster Ion Implantation. Nuclear Instruments and Methods in Physics Research Section B: Beam Interactions with Materials and Atoms, 307, 260-264. http://dx.doi.org/10.1016/j.nimb.2012.11.075 
[21] Zhang, R., Wang, Z.S., Zhang, Z.D., Dai, Z.G., Wang, L.L., Li, H., Zhou, L., Shang, Y.X., He, J., Fu, D.J. and Liu, J.R. (2013) Direct Graphene Synthesis on $\mathrm{SiO}_{2} / \mathrm{Si}$ Substrates by Ion Implantation. Applied Physics Letters, 102, 193102/1-4. http://dx.doi.org/10.1063/1.4804982

[22] Gutierrez, G., Muller, D., Antoni, F., Speisser, C., Aweke, F., Le Gall, Y., Lee, C.S., Cojocaru, C.S. and Le Normand, F. (2014) Multi-Layer Graphene Obtained by High Temperature Carbon Implantation into Nickel Films. Carbon, 66, 1-10. http://dx.doi.org/10.1016/j.carbon.2013.07.106

[23] Gutierrez, G., Le Normand, F., Aweke, F., Muller, D., Speisser, C. and Antoni, F. (2014) Mechanism of Thin Layers Graphite Formation by ${ }^{13} \mathrm{C}$ Implantation and Annealing. Applied Sciences, 4, 180-194. http://dx.doi.org/10.3390/app4020180

[24] Zhang, Y., Gomez, L., Ishikawa, F.N., Madaria, A., Ryu, K.M., Wang, C., Badmaev, A. and Zhou, C.W. (2010) Comparison of Graphene Growth on Single-Crystalline and Polycrystalline Ni by Chemical Vapour Deposition. The Journal of Physical Chemistry Letters, 1, 3101-3107. http://dx.doi.org/10.1021/jz1011466

[25] Sandstrom, P., Svedberg, E.B., Birch, J. and Sundgren, J.E. (1999) Structure and Surface Morphology of Epitaxial Ni Films Grown on MgO(111) Substrates: Growth of High Quality Single Domain Films. Journal of Crystal Growth, 197, 849-857. http://dx.doi.org/10.1016/S0022-0248(98)00972-5

[26] Nix, F.C. and MacNair, F. (1941) Thermal Expansion of Pure Metals: Copper, Gold, Aluminium, Nickel and Iron. Physical Review, 60, 597-605. http://dx.doi.org/10.1103/PhysRev.60.597

[27] Fiquet, G., Richet, P. and Montagnac, G. (1999) High-Temperature Thermal Expansion of Lime, Periclase, Corundum and Spinel. Physics and Chemistry of Minerals, 27, 103-111. http://dx.doi.org/10.1007/s002690050246

[28] Bailey, A.C. and Yates, B.J. (1970) Anisotropic Thermal Expansion of Pyrolitic Graphite at Low Temperatures. Journal of Applied Physics, 41, 5088-5090. http://dx.doi.org/10.1063/1.1658609

[29] Tsang, D.K.L., Marsden, B.J., Fok, S.L. and Hall, G. (2005) Graphite Thermal Expansion Relationship for Different Temperature Ranges. Carbon, 43, 2902-2906. http://dx.doi.org/10.1016/j.carbon.2005.06.009

[30] Stoquert, J.P., Pêcheux, F., Hervé, Y., Marchal, H., Stuck, R. and Siffert, P. (1998) VRBS: A Virtual RBS Simulation Tool for Ion Beam Analysis. Nuclear Instruments and Methods in Physics Research Section B: Beam Interactions with Materials and Atoms, 136-138, 1152-1156. http://dx.doi.org/10.1016/S0168-583X(97)00807-0

[31] Sandstrom, P., Svedberg, E.B., Birch, J. and Sundgren, J.E. (1999) Time-Resolved Measurements of the Formation of Single-Domain Epitaxial Ni Films on MgO(111) Substrates Using In-Situ RHEED Analysis. Surface Science, 437, L767-L772. http://dx.doi.org/10.1016/S0039-6028(99)00755-4

[32] Huez, M., Quaglia, L. and Weber, G. (1972) Fonction d’Excitation de la Réaction ${ }^{12} \mathrm{C}\left(\mathrm{d}, \mathrm{p}_{0}\right){ }^{13} \mathrm{C}$ entre 400 et $1350 \mathrm{keV}$ —Distributions angulaires. Nuclear Instruments and Methods., 105, 197-203. http://dx.doi.org/10.1016/0029-554X(72)90558-7

[33] Colaux, J.L., Thomé, T. and Terwagne, G. (2007) Cross Section Measurements of the Reactions Induced by Deuteron Particles on ${ }^{13} \mathrm{C}$. Nuclear Instruments and Methods in Physics Research Section B: Beam Interactions with Materials and Atoms, 254, 25-29. http://dx.doi.org/10.1016/j.nimb.2006.10.062

[34] Tuinstra, F. and Koenig, J.L. (1970) Raman Spectrum of Graphite. The Journal of Chemical Physics, 53, $1126-1131$. http://dx.doi.org/10.1063/1.1674108

[35] Malard, L.M., Pimenta, M.A., Dresselhaus, G. and Dresselhaus, M.S. (2009) Raman Spectroscopy in Graphene. Physics Reports, 473, 51-87. http://dx.doi.org/10.1016/j.physrep.2009.02.003

[36] Cancado, L.G., Jorio, A., Ferreira, E.H., Stavale, F., Achete, C.A. and Capaz, R.B. (2011) Quantifying Defects in Graphene via Raman Spectroscopy at Different Excitation Energies. Nano Letters, 11, 3190-3196. http://dx.doi.org/10.1021/nl201432g

[37] Ferrari, A.C. and Robertson, J. (2001) Resonant Raman Spectroscopy of Disordered, Amorphous, and Diamond Like Carbon. Physical Review B, 64, 075414-075426. http://dx.doi.org/10.1103/PhysRevB.64.075414

[38] Kalbac, M., Fahrat, H., Kong, J., Janda, P., Kavan, L. and Dresselhaus, M.S. (2011) Raman Spectroscopy and in Situ Raman Spectroelectrochemistry of Bilayer ${ }^{12} \mathrm{C} /{ }^{13} \mathrm{C}$ Graphene. Nano Letters, 11, 1957-1963. http://dx.doi.org/10.1021/nl2001956

[39] Tanuma, S., Powell, C.J. and Penn, D.R. (2004) Calculations of Electron Inelastic Mean Free Paths. V. Data for 14 Organic Compounds over the 50 - 2000 eV Range. Surface and Interface Analysis, 21, 165-176. http://dx.doi.org/10.1002/sia.740210302

[40] Shelton, J.C., Patil, H.R. and Blakely, J.M. (1974) Equilibrium Segregation of Carbon to a Nickel (111) Surface: A Surface Phase Transition. Surface Science, 43, 493-520. http://dx.doi.org/10.1016/0039-6028(74)90272-6

[41] Eizenberg, M. and Blakely, J.M. (1979) Carbon Monolayer Phase Condensation on Ni(111). Surface Science, 82, 228-236. http://dx.doi.org/10.1016/0039-6028(79)90330-3 
[42] Aweke, F., Hulik, J., Le Normand, F., Antoni, F., Speisser, C. and Morvan, G. (2015) Growth of Monocrystalline $\mathrm{Cu}(111)$ Films on MgO (111) by Pulsed Laser Deposition. Applied Surface Science, 336, 309-313.

\section{Supplementary Materials (SM)}

SM1: Kukichi EBSD patterns with planes assignations of (A, B): Ni/MgO_4 and (C, D): Ni/MgO_5 samples.

SM2: The ABC and ACB growth modes on $\mathrm{Ni(111)/MgO(111)} \mathrm{film.}$

SM3: AFM image of Ni/MgO(111)_1 sample before implantation.

SM4: SEM images on Ni/MgO_1 sample.

SM5: TLG fragments density as a function of the TLG mean area for of Ni/MgO_X samples $(1 \leq \mathrm{X} \leq 5)$.

SM6: EBSD polar figures before and after carbon implantation at $873 \mathrm{~K}$. 